\title{
Water availability in reference to water needs in Poland
}

\author{
Paulina Orlińska-Woźniak paulina.wozniak@imgw.pl \\ Paweł Wilk pawel.wilk@imgw.pl \\ Joanna Gębala joanna.gebala@imgw.pl \\ Institute of Meteorology and Water Management, National Research Institute, Podleśna Street 61, 01-673 Warszawa
}

\begin{abstract}
On Earth water is an irreplaceable asset, and an estimate of its resource capacity is necessary. The improper selection of indicators of water resources can lead to the underestimation or overestimation of the actual resources present. Incorrect assessments of water resources contribute to the improper completion of necessary water management tasks, thereby failing to satisfy the needs of different water users such as industry, agriculture and forestry, inland water navigation, tourism and recreation and the general population for the purposes of municipal water use. This article discusses the advantages of utilizing Earth Observation technology for estimating water resources in Poland. Despite the large amount of water on Earth, decades of wrongly pursued water management have led to a critical point in maintaining this valuable resource. According to actual estimations, there are enough fresh water resources in the world; the problem is the uneven distribution and pollution of these resources, especially in the case of surface water. Currently, Poland, in comparison with other European countries, is classified as a country with very little water resources. It is important, however, that a thorough evaluation using the latest measurement technologies is conducted, particularly for groundwater resources in deep layers of the lithosphere. The proper assessment of water resources requires knowledge of the hydrogeological conditions within each of the catchments of the analyzed area. International data sets are mostly incomplete and heterogeneous, which makes the comparison of data of several years difficult and often leads to mistakes. While analyzing Polish water resources several factors should be taken into account, including: the amount of rainfall, the amount of water in rivers, lakes and groundwater, and the above-mentioned factors affecting the measurement of the amount of disposable water resources. This article is an introduction to the broader analysis of water resources in Poland and an exploration of the issue from a different perspective.
\end{abstract}

Key words: estimation of water resources, water resources in Poland, water needs, water management, water deficit, GEOSS, GMES.

Submitted 17 October 2013, received 13 November 2013, accepted 14 November 2013

\section{Introduction}

Despite the vast amount of water on the planet, decades of unsustainable water management have caused water shortages that have reached crisis point in many regions. Globally, humans use more than $50 \%$ of all renewable and accessible freshwater, while, at the same time, billions of people still lack the most basic water services.

The balance between water demand and availability has reached a critical level in many areas of Europe, the result of prolonged periods of low rainfall or drought. Both water and population are unevenly distributed in Europe, and therefore countries and sub-regions experience differing degrees of water stress. The size of the average annual precipitation in the years 1940-1995 in Europe is shown in Fig. 1.

Water availability problems occur when the demand for water exceeds the amount available during a certain period. They occur frequently in areas with low rainfall and high population density, and in areas with intensive agricultural or industrial activity. Apart from water supply problems, overexploitation of water has led to the drying out of natural areas in western and southern Europe and salt-water intrusion in aquifers.

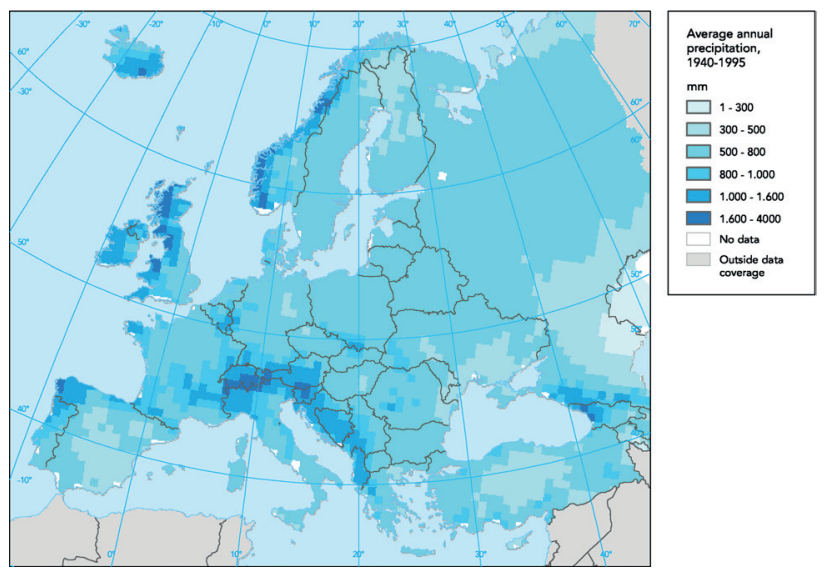

Figure 1. Average annual precipitation in the years 1940-1995 in Europe (source: EEA)

The indicator of water availability shows the possibility of water supply. This is the quotient of the average annual water runoff by rivers into the sea from a specific area and the number of people living in the area. Throughout the world, approximately 44 thousand cubic kilometers of water flows into the sea from rivers. Assuming the current state of the population on Earth is 6.3 billion people, we get an average water availability of 7000 cubic meters per cap- 


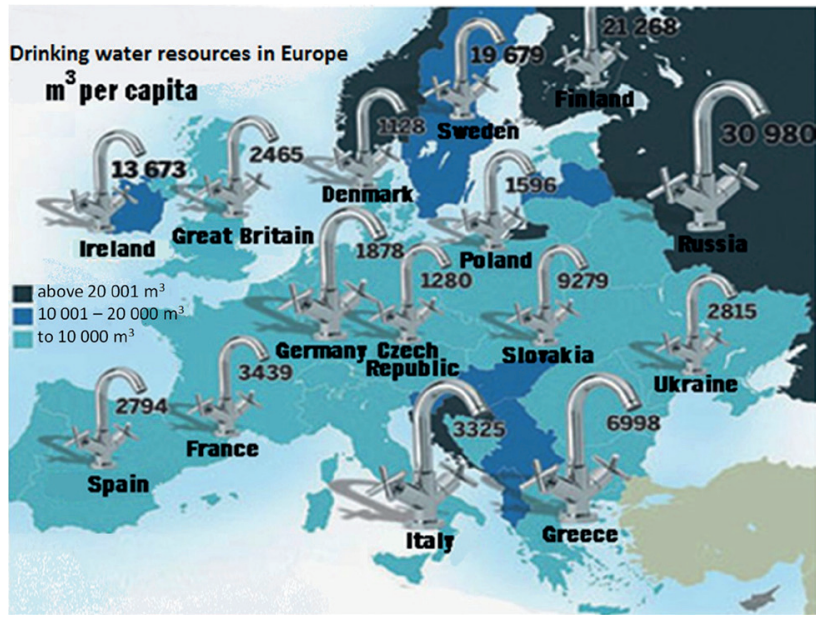

Figure 2. Drinking water resources in Europe in $\mathrm{m}^{3}$ per capita and year (source: GRID-Arendal)

ita and year. This is an amount of water that is completely sufficient to cover all municipal, industrial, agricultural or recreational water needs. Unfortunately, water resources are characterized by very unequal distribution in time and space. There are countries where the indicator of water availability exceeds several thousand cubic meters per capita and year, and countries where it is just a few cubic meters per capita and year. An additional impediment to water supply is the fact that the bulk of water flows through river during floodwaters, leaving a large body of water polluted and not suitable for any purpose. Drinking water resources in Europe are presented on Fig. 2.

\section{Water resources and water needs in Poland}

According to the principle of sustainable development, in terms of protecting water resources, and water management, water use depends on the state of water resources of a given country. Water resources are understood as general surface water and groundwater occurring permanently or temporarily in a particular area. The size and quality of these resources determines the economic development of societies and has an impact on the quality of life of individuals therein.

Water resources are sourced from different origins such as surface water, groundwater, precipitation or postproduction water. The same water can be repeatedly used (as in the power industry). Surface water, groundwater and rainwater resources are usually characterized by uneven distribution. The reasons for this variation are the topographical, geological and meteorological characteristics of an area, and various types of land use (Fig. 3). In addition, surface water and rainfall, apart from their spatial variability, are also characterized by a large, random variability in time, which is an aspect conditioned by meteorological phenomena. The annual cycle of these phenomena determines the average annual variation, both long term and within individual years. Renewability of water resources depends, inter alia, on the amount and intensity of precipi-

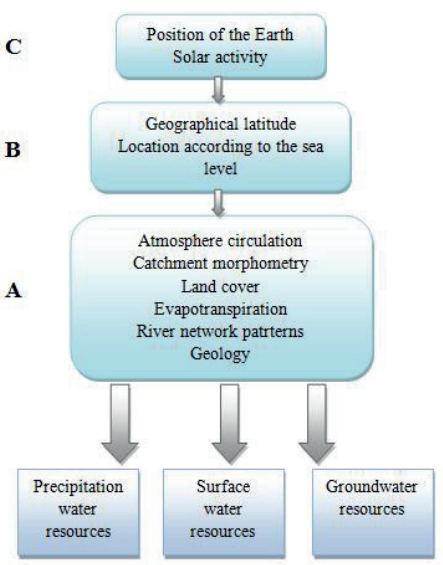

Figure 3. The main natural determinants of the water resources in $\mathrm{A}$ - local, B - over regional and C - global scale (PociaskKarteczka 2009)

tation, as well as on terrain, which affects the volume of surface and soil runoff.

The water balance of a country includes: precipitation $(\mathrm{P})$, evapotranspiration $(\mathrm{E})$ and river runoff $(\mathrm{H})$ at the surface $\left(\mathrm{H}^{\prime}\right)$ and underground (H"). The individual components constitute a general equation of water balance:

$$
\mathrm{P}=\left(\mathrm{H}^{\prime}+\mathrm{H}^{\prime \prime}\right)+\mathrm{E}
$$

Fig. 4 shows the total volume of water resources in European countries in comparison with the surface area of the country. It may be noted that the size of the country's surface area is directly proportional to the volume of water.

By the size of the total resources, in accordance with presented data, Poland is in 19th place among 29 countries analyzed, and in terms of precipitation in 11th place, following Austria, Switzerland, Ireland, Bulgaria and Romania. In terms of external flow, Poland is estimated to be in 17 th place among the 29 countries. Fig. 5 presents a summary of total water resources and total consumption volume area per $\mathrm{km}^{2}$.

Analysis of the amount of water in $\mathrm{hm}^{3}$ per unit area in $\mathrm{km}^{2}$ indicates the water resources in the country. Thus, the presented data enable an overview and comparison of different countries in terms of availability of surface water resources. Consequently, the obtained results characterized Poland as a country with relatively low water resources, as analyzed in this study. From the point of view of water use for the national economy, there is a distinction between water consumers (divisions of the national economy that consume water for production purposes) and water users (divisions of the national economy using water, but not consuming it). Consumers of water are the heat and power industries, municipal economies, agriculture and forestry. Water users are hydropower, navigation, tourism and recreation.

In Poland, the biggest water consumption is in the production of electrical energy and is associated with a high level of participation in coal energy production (cooling 


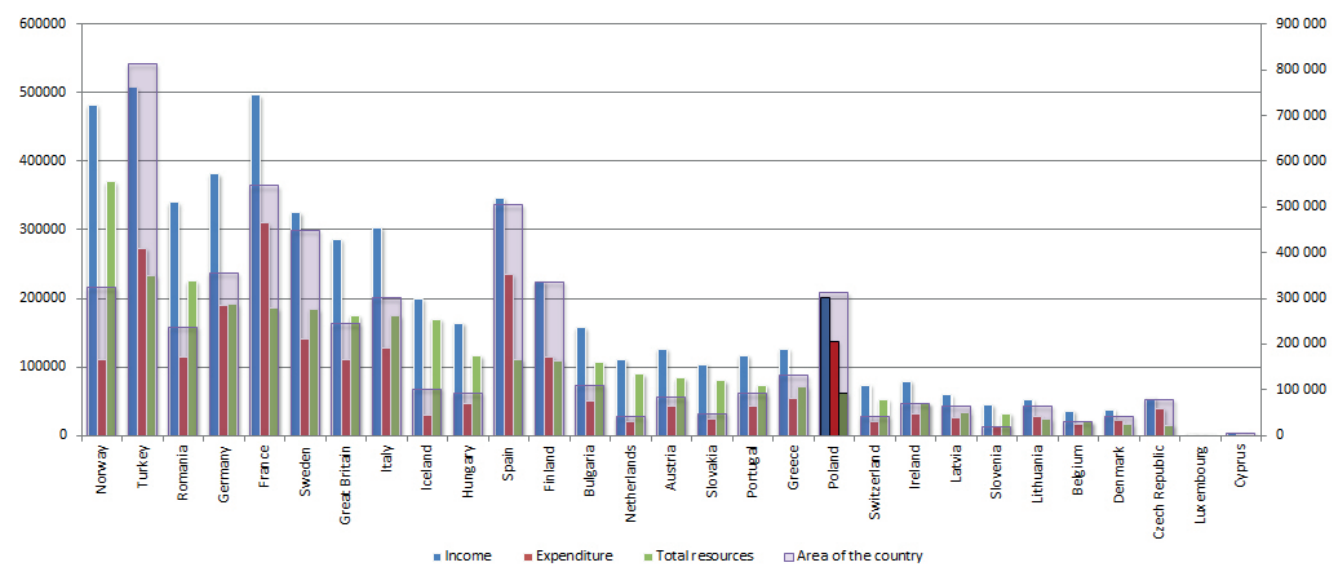

Figure 4. Total resources of diverse income and disbursements in selected EU countries against the background of their surface area (source: personal elaboration based on data from The World Bank)

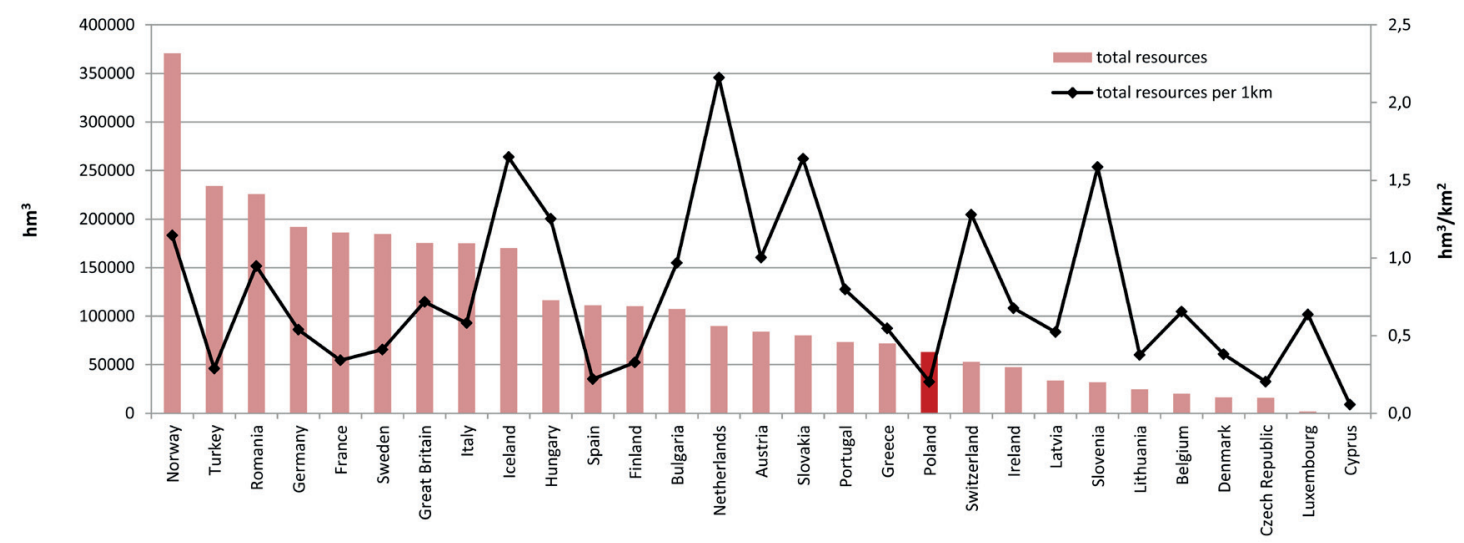

Figure 5. Summary of total water resources in $\mathrm{hm}^{3}$ and total volume of consumption in Poland per $\mathrm{km}^{2}$ compared to other countries (source: personal elaboration based on data from The World Bank)

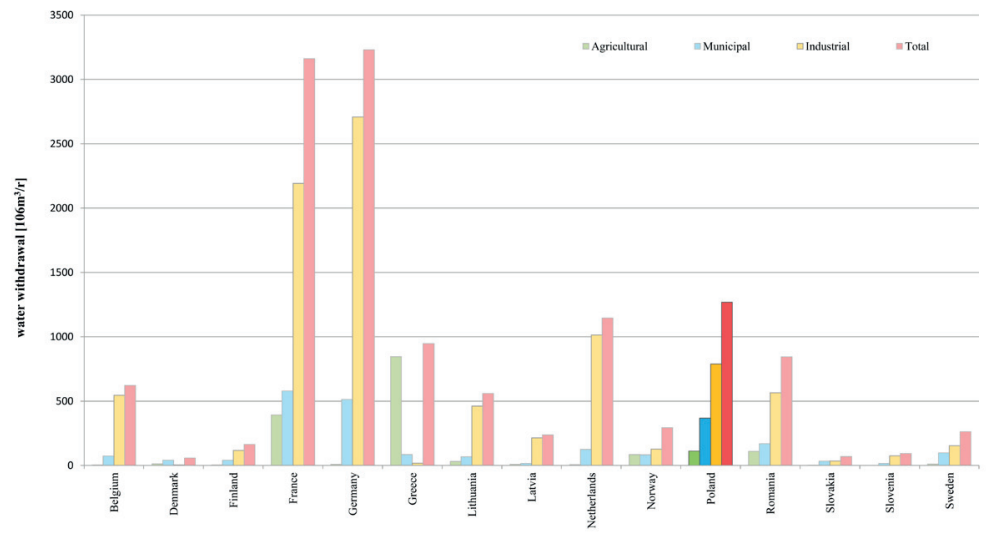

Figure 6. The size of water intake in the main sectors of the national economy against the background of selected EU countries (source: personal elaboration based on data from The World Bank)

processes). Poland now has a very low water consumption rate in agriculture, approximately twice as low as in Western European countries where a large portion of water consumption is spent on irrigation, something which in Poland is not required on this scale due to weather conditions. The structure of water consumption in the major sectors of the national economy in comparison with other countries according to FAO data is presented in Fig. 6.
Problems with water supply in Poland may also occur if agriculture, as in other Western European countries, collects more available water for irrigation than at present. However expectations in the coming years are that Poland will not be threatened by a water crisis, though water resources may be unevenly distributed - some regions may experience severe water shortages, and some may experience excess supply. 


\section{Estimation of water resources in Poland}

Analysis of the size of groundwater resources within the catchment requires knowledge of the conditions present and of the possibilities of discharge and renewal within each of the hydrogeological units. Due to the dynamics of groundwater, resources are distinguished as static or dynamic. Static resources are below the long-term and seasonal fluctuations of groundwater and, as gravitational water, fill the utility levels below the lower limit of seasonal and perennial groundwater fluctuations. They can be either renewable (in hydraulic contact with the surface area) or non-renewable (isolated from the surface of the terrain and other aquifers). An important aspect is that a correct assessment of deep groundwater resources involving the careful evaluation of those resources can change the assessment of the size of water resources in Poland (Mikulski 1998). Consumable surface water resources are difficult to estimate because of the possibility of re-utilization. International databases have limited or incomplete data and most importantly, are diverse in many respects. There is no homogeneous and comparable data for long time periods, which is something that could could be a meaningful basis for a more thorough analysis. Water resources of a country are usually measured by volume of water produced in a specific area in a defined period of time as a result of atmospheric processes (Kaczmarek 1978). In analyzing Polish water resources factors that must taken into account are: the amount of precipitation, river water supply, lakes and aquifers, and the abovementioned factors affecting the size of the disposable and consumable resources. Despite relatively small resources, the water deficit in Poland results not from a lack of water in general, but a lack of water in the right place and of adequate quality. Today, more frequent droughts are becoming a major concern for the country's economy. Moreover, increased demand for water is forecast.

The values characterizing water resources are constantly changing. This is caused by the variable set of characteristics of water as compared to other natural resources of the globe. The size of water resources depends on timevarying amounts of rainfall and on the physiographic conditions of the country. In the process of utilization of water resources, only a small amount is not returned into circulation and is conventionally defined as the non-refundable loss (except for the great consumption of water for evaporation). However, most of the water collected for different purposes goes back into circulation and is usually partially polluted.

\section{The consequences of poor water resource assess- ment}

Using the unit of $\mathrm{m}^{3}$ per capita and year, Poland has a high rate of water consumption equal to, according to FAO, 26.2\%. The indicator of water per capita and year is probably the best synthetic indicator, as it illustrates the richness of water as a resource for each country. But it must be recognized that despite its advantages it is not a convincing indicator. For a normal citizen, this hypothetical amount remaining at his disposal will usually exceed several times the need, but for planners and strategists this indicator does not show the direct action that should be taken. For creating water management strategies more detailed analyses related to the extreme periods, types of demand and average capacity of reservoir discharges, are needed. Improper selection of indicators of water resources can lead to the underestimation or overestimation of water available. This results in the mismanagement of water in the country, thereby adversely affecting the consequences of water allocation for different sectors of the economy. Incorrect estimation of water resources contributes to the improper realization of water management tasks, such as addressing the needs of different types of water users, including inter alia the population and the economy (industry, agriculture and forestry, hydro power, inland navigation, tourism and recreation). For non-consuming users it is not as significant as for consumers, like public utilities, agriculture and industry, for which it is sometimes a serious limitation to meeting their needs. Relative needs, which are replaceable, are the needs that can be met by substitutional solutions, while absolute water needs cannot be replaced in any way. Incorrect estimation of resources may also have a direct or indirect impact on prices of water, which can lead to a significant increase in economic costs. All the above-mentioned factors tend to reflect on changing the approach to estimating water resources in Poland, and thus to a change in the presentation and interpretation of the results of analysis, which should then affect the interpretation of the collected data and lead to better and wider opportunities for the utilization of these resources.

\section{The use of Earth observation systems for the proper assessment of water resources}

Space images of the Earth provide a wide range of information, impossible or difficult to obtain using groundbased systems. Applications of these images are rapidly increasing - from geodesy, cartography, oceanography, forestry or marine science to the study of climate change; these images aid in the attempts to respond in advance of threatening natural disasters, and in the assessment and effective management of their effects. The data obtained from satellite imagery can also be used to assess water resources. Remote sensing is a system of collecting information about objects and phenomena without direct contact with the sensor. Different methods of collecting information provide data that have complementary properties. For example, aeronautical images are characterized by precision and flexibility of implementation, and satellite images are useful for their global scale. Satellite Information is important in meteorological and water management measurement due to the width of the display, which allows wide scale observation and comparison of the results of simul- 
taneous measurement. Another advantage for meteorology is current data with the option of rapid updates. Data analysis provides, inter alia, the possibility of obtaining detailed data for monitoring drought nationwide. Remote sensing has a very wide range of applications. For resource and water management they include meteorological observations and weather forecasting, analysing changes in the environment to assess changes in climate processes, global warming and the impact of human activity, estimation of losses in reservoirs due to drought, floods, biological contaminations, information for the water cadastre, determination of the biological condition of the aquatic environment or the designation of areas exposed to flood hazards (Ryzenko et al. 2007).

Global Earth Observation System of Systems (GEOSS), coordinated by the GEO (Group on Earth Observations) is an international Earth observation system on land, sea, air and space designed to provide comprehensive data, information and analysis in the field of environmental science. GEOSS provides data and information in nine areas of societal benefits (SBAs), which are groups of complex issues that require accurate data on the spatial and temporal resolution. The main aims for these groups are:

- minimizing loss of life and property due to natural disasters and disasters caused by man,

- understanding the environmental factors affecting human health and well-being,

- improving management of energy resources,

- understanding, impact assessment, mitigation and adaptation to climate change,

- improving management of water resources through a more detailed analysis of the water cycle,

- improving the quality of weather information, forecasting and warning systems,

- improving management and protection of terrestrial, marine and coastal areas,

- promoting sustainable agriculture and combating desertification, as well as:

- understanding, monitoring and conservation of biological diversity.

Within the framework of GEOSS - GMES (Global Monitoring for Environment and Security) is being implemented. The program aims to provide information about the Earth's surface to maintain environmental sustainability. Subjects covered include the environmental monitoring of the oceans and atmosphere, as well as the Earth's surface including crop forecasting and the development of vegetation, providing an early warning system and guiding the use of water resources for the sustainable management of these elements. Another advantage is the integration of Earth observation data for GMES with products intended to support the implementation of policy and European directives. The products enable the provision and dissemination of information to support implementation of the Convention and also integrated models to prepare them for operational use (source European Commisison).
Pointing to the observations of water resources and the provision of information on their size, Earth observation technology allows for the examination of various factors. Satellite meteorological observations have great importance for estimating water resources. With relation to the meteorological processes in the atmosphere and their spatial and temporal dynamics, we should pay attention to the various possibilities of resolution imaging. The value of the resolution depends on the requirements of a particular analysis, namely the scale of meteorological phenomena, their dynamics, the possibility of classification and physical parameters. Imaging allows for the acquisition of information about fast-changing, as well as slow-changing, phenomena, and their mutual correlation and dependency (Ryzenko et al. 2007). Additionally, the study of water resources in soil layers is important when assessing drought. This is now difficult in Poland, due to scarcely available data and local character. Satellite observation gives us wide possibilities for estimating water resources on a global, holistic, detailed and reliable scale (Usowicz et al. 2009).

\section{Summary}

Potential water deficits in Poland result not from the lack of water in general, but from the lack of water in the right place and of adequate quality. Reservoirs in Poland, with a total capacity of about 4 billion $\mathrm{m}^{3}$, approximately $6.5 \%$ of average annual runoff volume, do not give full protection against floods and drought, and do not guarantee adequate water supply.

The estimation of water resources in Poland turns out to be a complicated process. Correctly determining water resources is very important in reference to water needs in Poland. Much incorrect estimation of the amount of water in Poland and the difficulty in specifying the issues have resulted in inappropriate and misguided concepts relating to the possible use of water in Poland. This has lead to unreasonable or inadequate water management. New research, analysis and technologies enable precise measurements of the amount of water circulating in the cycle of the various environmental factors such as atmosphere, pedosphere, biosphere and hydrosphere. A summary of the cumulative volume of water resources in the various components, including the availability of water for anthropogenic use, will allow a proper assessment of water resources in Poland. Such measurements are possible through the utilization of Earth observation technologies. These systems provide a global, accurate, comparable and reliable measurement of water resources. Only this approach will allow one to determine the amount of water in Poland and the place in which Poland ranks in terms of quantity of water in the world. 
Bibliography

European Environmental Agency, http://www.eea.europa.eu/ data-and-maps/figures/average-annual-precipitation, (access time: 14.10 .2011$)$

European Commission, www.ec.europa.eu, (access time: 25.10.2011)

GRID-Arendal, http:/www.grida.no/graphicslib/detail/waterresources-in-europe_92d1, (access time: 01.10.2011)

Kaczmarek Z., 1978, Zasoby wodne Polski i zasady ich racjonalnego wykorzystania, Nauka Polska, 8, 43-58

Mikulski Z., 1998, Gospodarka wodna, Wydawnictwo PWN, Warszawa

Pociask-Karteczka J., 2009, Water protection and water resources. Natural conditions and other aspects of water resources in river catchments - ad memoriam veterum veritatum, in:
Zasoby i ochrona wód - Obieg wody i materii w zlewniach rzecznych (ed. R. Bogdanowicz. J. Fac-Beneda), Fundacja Rozwoju Uniwersytetu Gdańskiego, Gdańsk, 15-36

Ryzenko J., Badurska A., Kobierzycka A., 2007, Kierunki rozwoju systemów satelitarnych, Polskie Biuro ds. Przestrzeni Kosmicznej, Warszawa, 23 pp

Struzik P., 2008, Satelity meteorologiczne od 40 lat w służbie Instytutu Meteorologii i Gospodarki Wodnej, Nauka Polska, 4, 35-42

The World Bank, http:/www.worldbank.org/, (access time: 23.09.2011)

Usowicz B., Marczewski W., Lipiec J., Usowicz J.B., Sokołowska Z., Dąbkowska-Naskręt H., Hajnos M., Łukowski M.I., 2009, Woda $\mathrm{w}$ glebie, pomiary naziemne i satelitarne w badaniach zmian klimatu, Polska Akademia Nauk, Warszawa, 171 pp 